\title{
Pricing of Vehicle-to-Grid Services in a Microgrid by Nash Bargaining Theory
}

\author{
Mohammad Hossein Sarparandeh and Mehdi Ehsan \\ Department of Electrical Engineering, Sharif University of Technology, Tehran, Iran \\ Correspondence should be addressed to Mohammad Hossein Sarparandeh; sarparandeh@ee.sharif.edu
}

Received 2 September 2016; Accepted 27 December 2016; Published 19 January 2017

Academic Editor: Linni Jian

Copyright (c) 2017 Mohammad Hossein Sarparandeh and Mehdi Ehsan. This is an open access article distributed under the Creative Commons Attribution License, which permits unrestricted use, distribution, and reproduction in any medium, provided the original work is properly cited.

\begin{abstract}
Owners of electric vehicles (EVs) can offer the storage capacity of their batteries to the operator of a microgrid as a service called vehicle-to-grid (V2G) to hold the balance between supply and demand of electricity, particularly when the microgrid has intermittent renewable energy sources. Literature review implies that V2G has economic benefits for both microgrid operator and EV owners, but it is unclear how these benefits are divided between them. The challenge grows when the policy makers rely on the V2G revenue as an incentive for expanding the penetration of EVs in the automotive market. This paper models the interaction between microgrid operator and EV owners as a bargaining game to determine how the benefits of V2G should be divided. The method has been implemented on a hybrid power system with high wind penetration in addition to diesel generators in Manjil, Iran. The results indicate that, in addition to V2G benefits, government subsidies are necessary to promote the use of EVs.
\end{abstract}

\section{Introduction}

Among the advantages which policymakers have enumerated for applying electric vehicles (EVs) in transportation are emission reduction and energy diversity of primary sources that generate electricity as a fuel for these vehicles $[1,2]$. These superiorities over the conventional gasoline-powered vehicle-whose fuel is dependent on finite oil reserveshave caused some experts to predict a bright future for EV market shares [3-6]. Nevertheless, some have argued that the additional cost of EVs is an obstacle to the adoption of this technology $[1,6,7]$.

The first solution to encourage large-scale utilization of EVs by customers might be subsidies. A subsidy of up to $\$ 7500$ by the US government is an example [7]. In addition, electric vehicle owners could earn money from providing a service called vehicle-to-grid (V2G), in which the electrical energy stored in their EV battery is injected to the grid whenever the grid operator calls on the vehicle owners for the service.

Since it is not feasible for a bulk power system operator to connect with a huge number of cars with insignificant power capacity, several papers have proposed an aggregator to be a middleman entity between vehicle owners and the system operator [8-15] -although the function of the aggregator in these papers is dissimilar. In this manner it would be possible for dispersed vehicles to participate in the electricity market, but the required communication infrastructure would be costly and widespread implementation of such a project would be a long-term program.

A more readily available application of $\mathrm{V} 2 \mathrm{G}$ is to use the storage capacity of EV batteries to mitigate the intermittency of renewable sources of electricity generation in a microgrid especially, with high penetration of renewable generation (e.g., wind or solar) as shown in [16-21]. In the short term, it is certainly more possible to provide the essentials for initiating V2G in microgrids, because a microgrid is a low extent power network whose communication and control system can easily deal with dispersed energy storage systems.

Although technical feasibility and economic profitability of V2G have been addressed in several studies, such as $[10,20-27]$, the division of benefits between the entity who utilizes V2G services and the vehicle owners is a point that has been missed in the literature. Although some studies 
like Lee and Park [28] tried to model interaction between EVs and a microgrid like a shopping mall, but indeed there is as of yet no proposed model on how the players of this bilateral agreement compromise. Since planners consider vehicle-to-grid as an incentive to promote EV penetration in the automotive market, it is vital to know how much impact V2G will have on each side of the contract. This paper offers a principle to be regarded in subsequent cost-benefit analyses of $\mathrm{V} 2 \mathrm{G}$.

The rest of the article is organized as follows. The advantages of incorporating the EV batteries storage capacity in a microgrid and its challenges are introduced in Section 2. Section 3 describes the Nash bargaining theorem and its application for division of added value to the microgrid due to V2G. Section 4 is devoted to a case study in which the benefits sharing model is utilized for a microgrid in Manjil, Iran. The subsequent results are presented in Section 5. Finally, some remarks and directions for future work are concluded in Section 6.

\section{Problem Description}

A microgrid is part of a local utility distribution network that uses distributed energy resources to supply electricity for associated local loads and can operate in either gridconnected mode or islanded mode. The microgrid operator controls the interconnection switch, loads, and distributed energy resources [29]. According to [30], distributed energy resources include distributed generation and distributed storage and often both are used to provide energy within the microgrid. Microgrids enhance power quality, reliability, and efficiency while lowering greenhouse gas emissions per unit of final energy consumed [31,32].

Although high penetration of renewable energy sources (e.g., wind turbines and photovoltaic panels) as distributed generation in a microgrid brings environmental benefits, but it may also jeopardize the balance between load and generation during islanded operation. A microgrid must be designed so that, in islanded mode, distributed energy resources can follow the load. Therefore, renewable sources of energy are usually installed in combination with diesel generators [33]. Distributed storage is considered as an alternative technology to reduce diesel generator size, as well as improving efficiency. When the renewable generation is high but the load is low, the excess power can be stored in a distributed storage system instead of being wasted as heat in dump loads. However, as [34] points out, connection of such storage systems to the grid requires smart control and advanced power electronic converters.

EV batteries are potential dispersed energy storage resources that may be viewed as an opportunity for microgrids with a high penetration of intermittent power generation sources. From a technical point of view, this requires communication and control infrastructure [9, 13, 35]; and from a commercial point of view, both microgrid operator and vehicle owner should derive a benefit. In terms of the microgrid operator, V2G decreases investment cost and operating cost due to a reduction in diesel generator size or other distributed energy resources required for load following. The additional costs of associated infrastructure should also be considered.

With respect to the vehicle owner, replacing a conventional car with an electric one has its costs (although government subsidies reduce the price gap). Moreover, V2G decreases the battery lifetime and accelerates battery replacement $[3,36,37]$. So the microgrid operator should pay the vehicle owners for the service and access the EV batteries so that V2G does not limit the vehicle functionality as a means of transport.

A model determining the amount of payment to vehicle owners by microgrid operator is described in the next section. The model must take into account the interests of both sides and investigate if the payment would be a sufficient incentive for the public to use the green technology of electric vehicles.

\section{V2G Benefits Sharing Model}

If the microgrid operator wants to contract with vehicle owners to use their EV batteries energy storage capabilities, it must reach an agreement on V2G service characteristics and price. The situation can be modeled by game theory as a bargaining game with the microgrid operator and all vehicle owners as players. It has specifications of a bargaining game, because the players benefit from cooperation as discussed in previous section, but at the same time the microgrid operator wants to pay less to vehicle owners while the vehicle owners want to gain more fee. There are many vehicles in this game and this increases the complexity, but it is possible to consider a single representative, as it is considered in [38-40], for a wage bargaining game. In a wage bargaining game, a firm and a union-that is representative of all workers-bargain over the division of profits between them. In our problem, all vehicle owners have similar interests and the interaction of their community with the microgrid operator affects the price and specifications of the V2G service contracts, so their community can be assumed as a single player against microgrid operator as the other player. Before describing the model proposed in this paper, we review the theory of bargaining and Nash bargaining solution.

3.1. Nash Bargaining Theory. A bargaining problem with two players describes a situation in which both players are motivated to cooperate, although there is a conflict of interest about agreement terms. Bargaining theory was formally introduced by John Nash in 1950 by an axiomatic (or cooperative) approach and followed by the strategic (or noncooperative) framework with alternating offers by Rubinstein in 1982 [38].

The axiomatic approach presented by Nash sets a series of axioms (i.e., properties that characterize the solution) and the solution must satisfy these axioms. In the strategic approach, players offer alternating proposals to each other. So the bargaining is modeled as a sequential game with an infinite bargaining horizon where delays in agreement lead to reduced payoffs. According to [38], the Rubinstein model is suitable for strategic relationships arising in dynamic (i.e., over time) negotiations in which there is no foreseeable deadline. In contrast, the Nash solution explains a situation 
where bargainers sign a binding contract once an agreement is struck.

The Nash solution of a bargaining game is a mutually beneficial agreement that maximizes the product of players' excess payoffs due to agreement. In other words, considering $\dot{P}_{1}$ and $P_{2}$ as the payoffs of players when there is no agreement, $P_{1}$ and $P_{2}$ will be the Nash solution of the bargaining game if and only if they maximize the term in

$$
\max _{P_{1}, P_{2}}\left(P_{1}-\dot{P}_{1}\right) \times\left(P_{2}-\dot{P}_{2}\right)
$$

The Nash solution is Pareto optimal, so there is no agreement in which the utilities of both players are simultaneously more than $P_{1}$ and $P_{2}$.

3.2. The Two-Stage Model Formulation. If we want to apply Nash bargaining theory to the $\mathrm{V} 2 \mathrm{G}$ pricing problem in a microgrid, we have to determine the payoffs of both microgrid operator and vehicle owners union, with and without V2G. Payoffs can be expressed by monetary unit. Time value of money should be taken into consideration. Costs as well as revenues form a cash flow and are discounted using an interest rate for an analysis period.

The formula for Nash bargaining is presented in

$$
\begin{gathered}
\max _{N, p}\left(\mathrm{MGC}_{\text {base }}-\mathrm{MGC}_{\mathrm{V} 2 \mathrm{G}}-N \times p\right) \\
\times(N \times \mathrm{CVC}-N \times \mathrm{EVC}+N \times p),
\end{gathered}
$$

where $\mathrm{MGC}_{\text {base }}$ is the net present cost of investment and operation of the microgrid without $\mathrm{V} 2 \mathrm{G}, \mathrm{MGC}_{\mathrm{V} 2 \mathrm{G}}$ is the net present cost of investment and operation of the microgrid utilizing V2G, $p$ is the present value of payment to the vehicle owners for $\mathrm{V} 2 \mathrm{G}$ service by the microgrid operator, $N$ is the number of electric vehicles that participate in V2G, CVC is the net present cost for buying and keeping a conventional gasoline-powered vehicle (including fuel cost), and EVC is the net present cost for buying and keeping an electric vehicle (including fuel cost).

In (2) $N$ and $p$ are decision variables. Therefore, the number of vehicles and V2G price should be determined simultaneously to maximize the Nash product. Alternatively, decision variables can be determined sequentially by a twostage model in which the optimum number of electric vehicles for V2G is appointed first through minimizing the term denoted in (3). Then the Nash product in (2) is maximized with respect to $p$, while $N$ is assumed to be fixed. It can be proved that both alternative methods have similar results (see Appendix). In (3), the total cost of the microgrid operator and electric vehicle union for replacing vehicles and utilizing V2G is minimized. This means that players should consider global utility to set $N$ and then bargain over $p$.

$$
\min _{N}\left(\mathrm{MGC}_{\mathrm{V} 2 \mathrm{G}}(N)+N \times(\mathrm{EVC}-\mathrm{CVC})\right)
$$

By solving (2) with respect to $p$, the payment to the vehicle owners for V2G service will be specified as presented in

$$
\begin{aligned}
& p \\
& =\frac{1}{2}\left(\mathrm{MGC}_{\text {base }}-\mathrm{MGC}_{\mathrm{V} 2 \mathrm{G}}+N \times \mathrm{EVC}-N \times \mathrm{CVC}\right) .
\end{aligned}
$$

Hence, the proper V2G price will be revealed dependent on the pricing scheme and regarding $p$ as the present value of total payment for V2G to each electric vehicle.

\section{Case Study: A Microgrid in Manjil, Iran}

Manjil, a city located in the north of Iran, has wind farms that deliver electricity to the national grid. Commonly facing power interruptions, feasibility studies have been conducted since 2010 to investigate if the Manjil distribution network could supply its local critical load when it is isolated from the national grid in rare events that may occur a few hours a year. Local wind turbines were presumed as one of the power generation sources in the incoming microgrid. Intermittency and variability of wind power oblige the utilization of a complementary diesel generator to maintain a steady balance of supply and demand. Determining the size of the diesel generator for the microgrid in Manjil was a multiobjective decision-making problem whose goal was finding the optimal MW rating that ensures the reliability of the microgrid with minimum cost. The problem has been discussed in [41] in detail.

As mentioned in the previous sections, V2G can be considered as an alternative energy source which will decrease the diesel generator size and consequently the investment cost of the microgrid. If the Manjil microgrid wants V2G to be applied in the island mode of operation, the payment to vehicle owners should be agreed so that it is mutually beneficial. Hence, the previously introduced two-stage model has been utilized to compute the V2G price. It should be noted that the pricing scheme proposed in this paper can be applied to various cases other than Manjil too.

According to the first stage, the optimum number of electric vehicles participating in V2G must be calculated at the beginning. The reduced MW rating of the diesel generator is derived in the same stage to be compared with the initial rating. Therefore, two cases have been analyzed for planning of Manjil microgrid in island mode of operation. Both cases use two $660 \mathrm{~kW}$ Vestas wind turbines. Case 1 is the base case in which a diesel generator adjoins when the microgrid is isolated from grid. The size of the diesel generator is the only decision variable in the design of the base case. In Case 2 , electric vehicles service the microgrid; thus the decision variables in this case are the number of vehicles and the modified size of the diesel generator. Figure 1 demonstrates the configuration of the Manjil microgrid.

Wind speed data for Manjil has been recorded in 10minute time steps in 2009. The time series for wind power generation is derived from wind speed data and the power curve of the turbine generators. The yearly peak load in Manjil is about $5 \mathrm{MW}$, but in island mode-which may last up to 6 


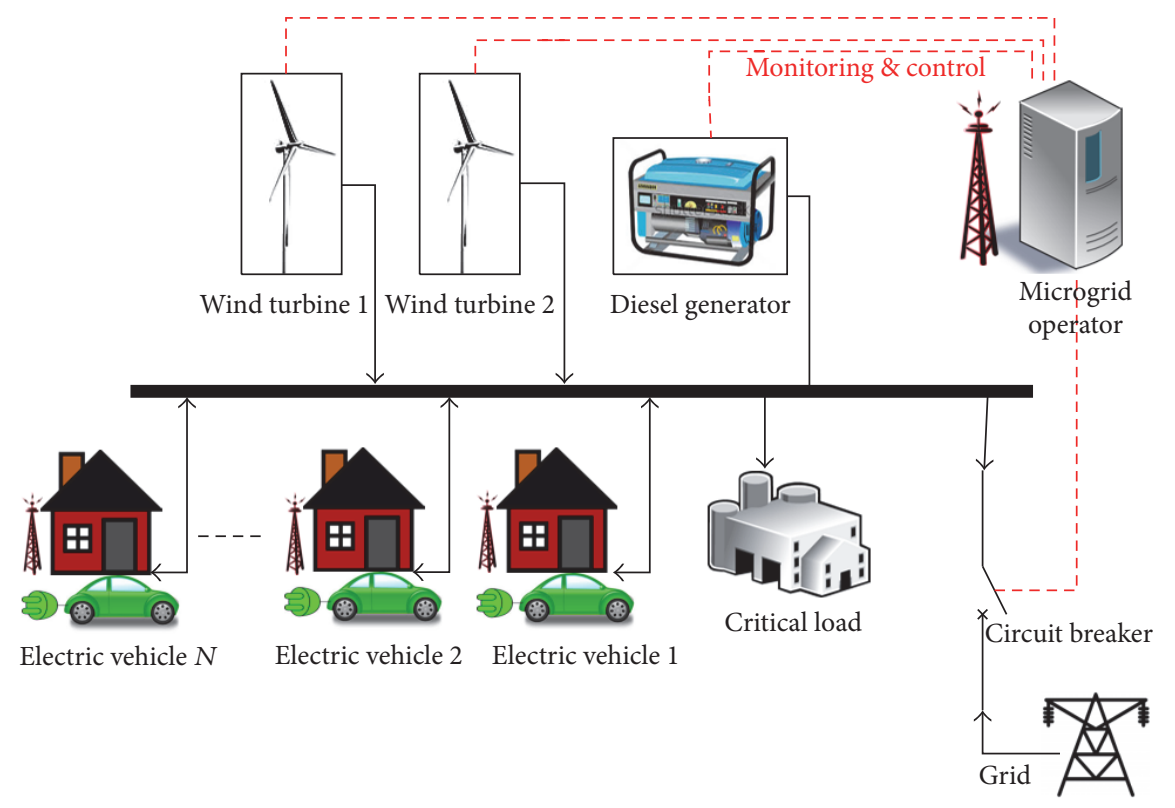

Figure 1: Configuration of Manjil microgrid.

hours-only the critical load, approximately $20 \%$ of the total load, must be supplied.

Sizing of microgrid components is dealt with as a multiobjective problem by the NSGA-II algorithm in MATLAB. Reliability and cost are the two objectives that form the axis of Pareto front (a set of solutions with no other solution which can improve at least one of the objectives without degrading any other objective [42]) as output of the program. "System minutes" is selected as the reliability index. The operating cost of the diesel generator is negligible, since the diesel generator is only operated in island mode and isolation of Manjil from the grid is infrequent and of a short duration. So its operating cost is much less than its investment cost and can be neglected. Operating cost of the wind turbines is negligible, too. The investment cost of wind turbines is not considered in the planning problem, because they are present in the Manjil wind farm now and are operated all year long. All other costs are accounted and transferred in cash flow to the present value.

The optimum value for decision variables in each case has been found using a hybrid method which is a mixture of simulation and multiobjective optimization. The advantage of simulation as stated in [43] is studying the details that cannot be easily considered by other methods. If the alternatives or potential solutions are limited, the most appropriate way to find the best solution is to simulate all of them. But when the solution space is extended, it would be too time consuming to simulate all possible solutions. In such circumstances, a heuristic search of the solution space is beneficial.

One of the methods that can intelligently search the solution space is the genetic algorithm which is compatible with multiobjective optimization. NSGA-II is a controlled elitist genetic algorithm. As it is elitist, it prefers solutions with better fitness values. As it is controlled, it also favors the solutions that increase the diversity of the population.
Diversity of population helps the algorithm converge to an optimal Pareto front.

Thus, the steps of the algorithm for finding the size parameters can be summarized as follows:

(1) Random generating of an initial population for decision variables (initial values for size of diesel generator and number of electric vehicles)

(2) Simulating the operation of the microgrid with defined decision variables and evaluating the fitness of solutions according to prescribed criteria (reliability and cost)

(3) Investigating the termination criteria and moving to Step (5) if they have been satisfied

(4) Intelligent selection of next generation of solutions with genetic algorithm and returning to Step (2)

(5) Plotting the optimal Pareto front

Simulation of each solution, which is equivalent to a specific design, is performed with 10-minute time steps for a 6-hour interval in which the microgrid is operated in island mode. Due to the random nature of wind speed and its different patterns in various months of the year, four 6-hour intervals are randomly picked for each month and the fitness values would be eventually obtained from the average of 48 present scenarios. The algorithm termination criteria include a combination of the maximum number of generations, time constraints, and lack of significant improvement in fitness values. The output of the program is a Pareto front for each case whose horizontal axis denotes cost and whose vertical axis denotes the reliability index. All points on the Pareto front may be viewed as an optimal point. For final decision making, one can set the desired reliability index and compare the present values of total cost associated with each case. 
To simulate the operation of the microgrid as the second step in the algorithm used to find the optimum number of electric vehicles, it is necessary to model the microgrid components (i.e., diesel generator, wind turbines, electric vehicles, and critical load) and the relationships between these components. As mentioned before, for the power generated by wind turbines and the power consumed by critical load, a simulated time series vector has been utilized. For electric vehicles, their batteries are considered as energy storage systems that can be charged with at most $3 \mathrm{~kW}$ power from the grid and deliver at most the same power to the grid when necessary. The rating of vehicle batteries' energy size is assumed to be $12 \mathrm{kWh}$. Both charging efficiency $\left(\eta_{c}\right)$ and discharging efficiency $\left(\eta_{d}\right)$ are considered to be 0.95 which results in a round-trip efficiency of approximately 0.9 .

Regarding the interaction between electric vehicles and microgrid operator, it is also accepted that V2G would only be used when the microgrid switches to island mode. Hence, the convenience of electric vehicle owners will not be influenced, except for a limited number of days when the microgrid is disconnected from the bulk power grid. During the period of disconnection, the battery charge/discharge control of the electric vehicles that have contracted to participate in V2G and are available to the grid will be performed by the microgrid operator. Available vehicles are those which are parked and connected to the grid. The availability index, which has been defined as the ratio of available vehicles to the total vehicles under contract, is 70 percent. In $[11,16$, $44]$, some statistical information has been provided about how many hours the cars are parked in a day. The required communication and control infrastructure for monitoring, data acquisition, and sending control commands to electric vehicles should be provided by the microgrid operator.

In simulating the microgrid operation, critical load level and wind speed have been considered as exogenous variables. What the microgrid operator has under his control includes the amount of power generated by the diesel generator and the charge/discharge rate of power to/from the vehicle batteries. The strategy applied in this paper to adjust charge levels of vehicle batteries is intended to maximize the energy reserved in the batteries. Therefore, in every time step in which the vehicle batteries are not fully charged and total output power of the wind turbines plus maximum power of the diesel generator exceeds the critical load level, batteries will be charged. This helps sufficient energy to be available in the batteries for the next time steps with a probable shortage in wind power. Hence, a new parameter has been defined called the power absorption capability (PAC) of vehicle batteries whose quantity in each time step is obtained from

$$
\operatorname{PAC}(t)=\sum_{i=1}^{N} \min \left(P_{b_{i}}, \frac{\left(1-\mathrm{SOC}_{i}(t)\right) \times E_{b_{i}}}{\eta_{c} \times T}\right),
$$

where $N$ is the number of electric vehicles, $P_{b_{i}}$ is the nominal power of the $i$ th battery converter in $\mathrm{kW}, \mathrm{SOC}_{i}(t)$ is the state of charge for $i$ th vehicle battery at time step $t, E_{b_{i}}$ is the capacity of $i$ th vehicle battery in $\mathrm{kWh}, \eta_{c}$ is the charging efficiency of $i$ th vehicle battery, and $T$ is the time step duration in $h$.

At this stage, if total power generation of wind turbines is greater than critical load plus $\operatorname{PAC}(t)$, the wind turbines will be disconnected one by one, until the consumption surpasses the generation. Then, the rate of power that must be generated by the diesel generator can be obtained from

$$
P_{d}(t)=\min \left(P_{d_{\max }}, L(t)-\sum_{i=1}^{N_{w}} P_{w_{i}}(t)+\operatorname{PAC}(t)\right),
$$

where $P_{d}(t)$ is the power generated by the diesel generator at time step $t$ in $\mathrm{kW}, P_{d_{\max }}$ is the maximum power of the diesel generator in $\mathrm{kW}, L(t)$ is the amount of critical load at time step $t$ in $\mathrm{kW}, N_{w}$ is the number of wind turbines that are still connected, and $P_{w_{i}}(t)$ is the power generated by $i$ th wind turbine at time step $t$ in $\mathrm{kW}$.

Afterwards, the microgrid operator will determine the power which should be exchanged with the electric vehicles union from

$$
P_{\mathrm{V} 2 \mathrm{G}}(t)=L(t)-\sum_{i=1}^{N_{w}} P_{w_{i}}(t)+P_{d}(t) .
$$

When $P_{\mathrm{V} 2 \mathrm{G}}(t)$ is positive, it means that the power generated by the diesel generator and wind turbines is not sufficient for supplying load, so the microgrid operator orders the electric vehicles to deliver electricity to the microgrid. Nevertheless, it is possible that some part of the load has to be interrupted. The amount of interrupted load may be calculated from (8). When $P_{\mathrm{V} 2 \mathrm{G}}(t)$ is zero, the batteries of electric vehicles connected to the grid are fully charged and when $P_{\mathrm{V} 2 \mathrm{G}}(t)$ is negative, it means that vehicle batteries can be charged, because of adequate power supply. An allocation scheme for $P_{\mathrm{V} 2 \mathrm{G}}(t)$ among electric vehicles is beyond the scope of this paper

$$
\operatorname{ENS}(t)=L(t)-\sum_{i=1}^{N_{w}} P_{w_{i}}(t)+P_{d}(t)+P_{\mathrm{V} 2 \mathrm{G}}(t) .
$$

In the above equation, ENS $(t)$ is the energy not supplied at time step $t$ in $\mathrm{kWh}$. The total energy not supplied during all time spans for 48 simulation scenarios forms the reliability index as one of the design criteria. Total cost, the second decision criterion, is obtained from

$$
\mathrm{TC}=P_{d_{\max }} \times \pi_{d}+N \times \pi_{\mathrm{EV}}
$$

where TC is the total cost in $\$, \pi_{d}$ is the diesel generator investment unit price which is supposed to be $\$ 800 / \mathrm{kW}$, and $\pi_{\mathrm{EV}}$ is the surplus cost of an electric vehicle with respect to a conventional gasoline-powered vehicle in $\$$, with regard to government subsidies. The reasons for not considering other parameters in determining the total cost had been discussed above. The required cost for installing the communication and control infrastructure to implement V2G has been accounted in $\pi_{\mathrm{EV}}$.

To compare the cash flows of conventional and electric vehicles, it should be noted that the lifetime of an automobile 
in Iran is about 20 years. The lifetime of the diesel generator and analysis time span is assumed to be 20 years, too. An electric vehicle is almost $\$ 6000$ more expensive to buy and needs battery replacement in the tenth year. It is assumed that the cost of battery replacement is $\$ 6000$ and the cost of establishing the infrastructure for V2G is $\$ 1000$ per vehicle. On the other hand, a typical PHEV consumes approximately 0.05 liter $/ \mathrm{km}$. In comparison with a 0.08 liter $/ \mathrm{km}$ fuel consumption rate for a conventional vehicle and assuming an average distance traveled of 30,000 kilometers per year, there will be a 900-liter-per-year difference. The gas price in Iran is about $\$ 0.3 /$ liter which gives a $\$ 270$ per year cost reduction by replacing a conventional vehicle with an electric one. Therefore, $\pi_{\mathrm{EV}}$ is equivalent to the present value of the cash flow as shown in the following equation:

$$
\pi_{\mathrm{EV}}=\pi_{s}+\pi_{i}+\pi_{b} \times \frac{1}{(1+i)^{10}}-\pi_{f} \times \frac{(1+i)^{20}-1}{i \times(1+i)^{20}}
$$

where $\pi_{s}$ is the price difference between an electric vehicle and a conventional one, $\pi_{i}$ is the V2G infrastructure cost per vehicle, $\pi_{b}$ is the battery replacement cost, $\pi_{f}$ is the annual cost reduction due to fuel saving of an electric vehicle, and $i$ is the discount rate in Iran that may reasonably be approximated with 20 percent in 2014. Hence, $\pi_{\mathrm{EV}}$ in this case is about $\$ 6654$.

\section{Results}

The results of the analysis for Manjil show that utilization of electric vehicles with the current price difference between conventional cars and electric cars-which is mainly due to battery costs-is not economically attractive even when considering the benefits of V2G. One can only hope that widespread use of electric vehicles in the short term may be a possibility if the government provides a subsidy for buying electric vehicles in order to protect the environment and promote green technologies. Unfortunately, according to calculations made in this study, any subsidy less than $\$ 5000$ per electric vehicle would not encourage the public to buy an electric car. Figure 2 demonstrates the optimal Pareto fronts of microgrid sizing plans for various scenarios. The horizontal axis in this figure illustrates the equivalent present value of the plan, while the vertical axis represents the reliability index expressed in system minutes.

Figure 2 shows four scenarios: in the first one, vehicle batteries are not utilized and the Pareto front has been extracted from various designs with different diesel generator power sizes. In other scenarios, vehicle batteries are used to supply load along with a diesel generator as the complements to wind turbines. In one of these three cases, there is no government subsidy, but in the other two scenarios, the subsidies equal to $\$ 5000$ and $\$ 5500$ have been assumed. In Figure 3, a scenario with a $\$ 6000$ government subsidy is added to the previous figure. If the government subsidy was more than $\$ 6654$, buying an electric vehicle became economically attractive, even without receiving V2G income. The results of analyzing this case indicate that, considering

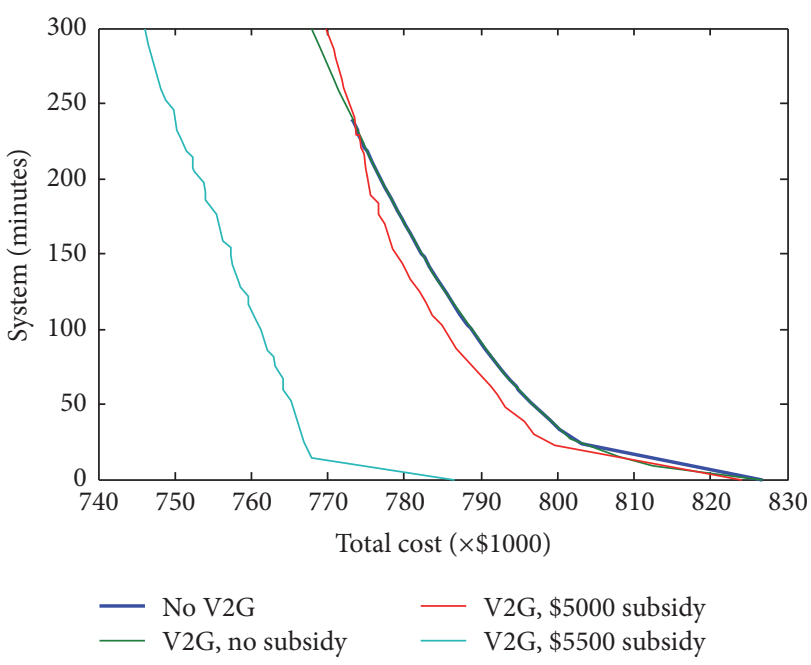

FIGURE 2: Optimal Pareto fronts of microgrid sizing plan for various scenarios.

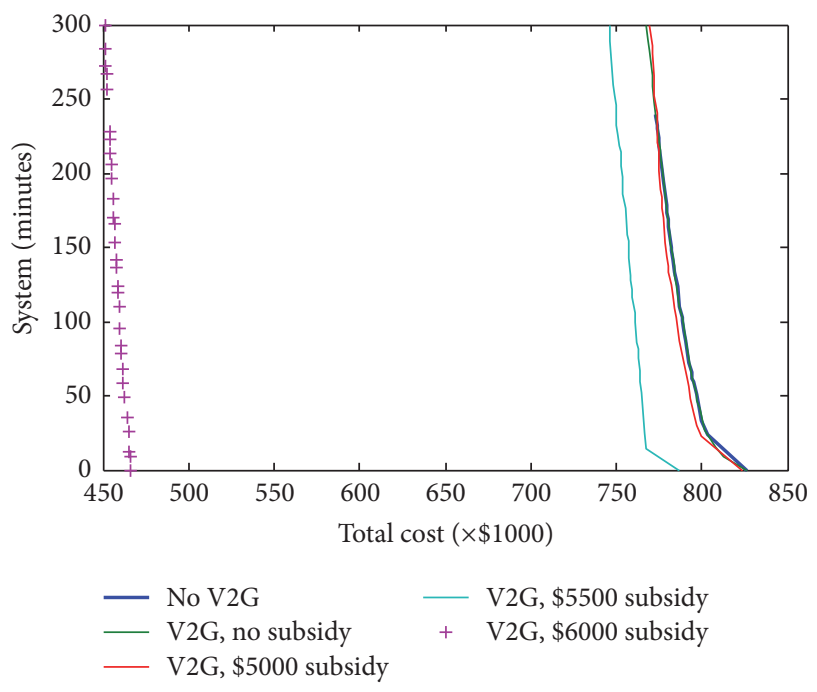

FIGURE 3: Optimal Pareto fronts with a new scenario: $\$ 6000$ subsidy.

the proceeds of V2G, a $\$ 6000$ subsidy is an appropriate decision.

One way to attain a certain design for sizing of microgrid components among the optimal options on Pareto front is to specify a minimum requirement for reliability. In this paper, the system minutes index is supposed to be less than 30 minutes in a year as a decision criterion. Accordingly, Table 1 has been obtained for various scenarios of the problem.

As it is shown in Table 1 , a subsidy of $\$ 6000$ has a large impact on the optimal design of the system and the investment cost needed to meet the load. In the rest of this paper, it has been assumed that this amount of subsidy will be granted from the government to everyone who buys an electric vehicle. Therefore, for determining the price of V2G services via the Nash bargaining theory, two cases have been studied and compared: first, operation of the microgrid without V2G and second, operation of the microgrid with 
TABLE 1: Size, cost, and reliability indices for various scenarios.

\begin{tabular}{|c|c|c|c|c|c|}
\hline Scenario & No V2G & V2G (no subsidy) & V2G ( $\$ 5000$ subsidy) & V2G ( $\$ 5500$ subsidy) & V2G ( $\$ 6000$ subsidy) \\
\hline System minutes & 29.2 & 29.8 & 29.0 & 29.0 & 29.9 \\
\hline Microgrid inv. cost (\$) & 801100 & 801000 & 663096 & 635281 & 44543 \\
\hline Total cost $(\$)$ & 801100 & 801000 & 797070 & 749527 & 461795 \\
\hline Diesel generator size (MW) & 975.0 & 974.9 & 805.0 & 770.8 & 53.3 \\
\hline Number of PHEVs & 0 & 0 & 81 & 99 & 638 \\
\hline
\end{tabular}

TABLE 2: Results for V2G service pricing.

Equivalent present value of total V2G service price

$\$ 586904.5$

Equivalent present value of $\mathrm{V} 2 \mathrm{G}$ service price per vehicle

$\$ 919.913$

Equivalent annual payment to each vehicle for V2G service

$\$ 188.91$

Excess payoff of microgrid operator due to $\mathrm{V} 2 \mathrm{G}$

$\$ 169652.5$

Excess payoff of each vehicle owner due to V2G

$\$ 265.913$

Payment to each vehicle per hour available

$\$ 44.9786$

V2G and the government subsidy (\$6000). In Figures 4(a)$4(\mathrm{~d})$, the results of simulating the system during a six-hour interval of isolation from grid for both cases in a windy condition are depicted. Figures $5(\mathrm{a})-5(\mathrm{~d})$ display the results of the simulation for both cases in a low wind six-hour time interval.

As can be seen in Figures 4 and 5, when only the diesel generator is used to follow the difference between the power generated by wind turbines and the power consumed by load, a high capacity of diesel generator is needed to be installed. When charge/discharge power of the vehicle batteries follows the load, a low capacity of diesel generator is required and it will work with an almost smooth output power. When the electric power generated by wind turbines is high, the batteries' state of charge will be approximately invariant. However, when the wind speed drops, the vehicle batteries will gradually discharge. The possibility of storing extra power generated by wind turbines in vehicle batteries eliminates cutting of wind turbines due to excess power in island mode. This enhances the energy efficiency in the microgrid.

Using (4) and the results listed in Table 1, the price of vehicle-to-grid service, revenues, and profits of the microgrid operator and electric vehicle owners from V2G agreement is shown in Table 2.

In Table 2, the first row represents the equivalent present value of the total payment by the microgrid operator to all vehicle owners during a 20-year time interval for participating in the vehicle-to-grid program. The second row indicates the same parameter per vehicle, while the price in the third row is the equivalent annual payment by the microgrid operator to each vehicle during the 20 -year period, given a discount rate equal to $20 \%$. Excess payoffs of the microgrid operator and vehicle owners due to V2G implementation are listed as equivalent present values. In the last row, it has been assumed that the pricing scheme is based on the hours that an electric vehicle is available for V2G when it is called for. Percentage of available vehicles is supposed to be $70 \%$ and it is assumed that isolation from grid takes place for on average 6 hours a year. Hence a vehicle owner would be paid about $\$ 45$ for one-hour availability.

\section{Conclusion}

The utilization of batteries of electric vehicles as energy storage systems can help microgrids in supplying load when they become isolated from the grid. This service, which is known as V2G, requires the active participation of electric vehicle owners. To develop and maintain such partnerships, the interests of both microgrid operators and vehicle owner should be considered. Otherwise, the participants would not have sufficient motivation. This paper has proposed a model to determine how to divide the proceeds of V2G among its contributors based on Nash bargaining theory. The output of the model specifies the optimum number of electric vehicles and the amount of money that must be paid by the microgrid operator to the electric vehicle owners which has been interpreted as the V2G service price. Moreover, this model can be used to determine the appropriate rate for subsidies granted by the government to promote the purchase of electric vehicles.

The results of implementation of the proposed model in the Manjil case in Iran indicate that, to encourage the public to buy electric vehicles, it is essential that the government compensate much of the cost difference between conventional and electric vehicles in the form of subsidies. The remaining difference can be compensated by the revenues of the electric vehicle owner from V2G service. The microgrid operator will earn a profit from a reduction in the amount of investment necessary for supplying critical load by diesel generator in emergencies. This profit will be shared with the vehicle owners.

This paper has analyzed the V2G service pricing problem for a case in which the vehicle batteries are utilized only whenever the microgrid goes into island mode. Since such a situation rarely happens in a year, vehicle owners will not be inconvenienced and battery depreciation cost due to frequent charge/discharge cycles will be negligible. For future study, one could also develop a model for V2G service pricing in 


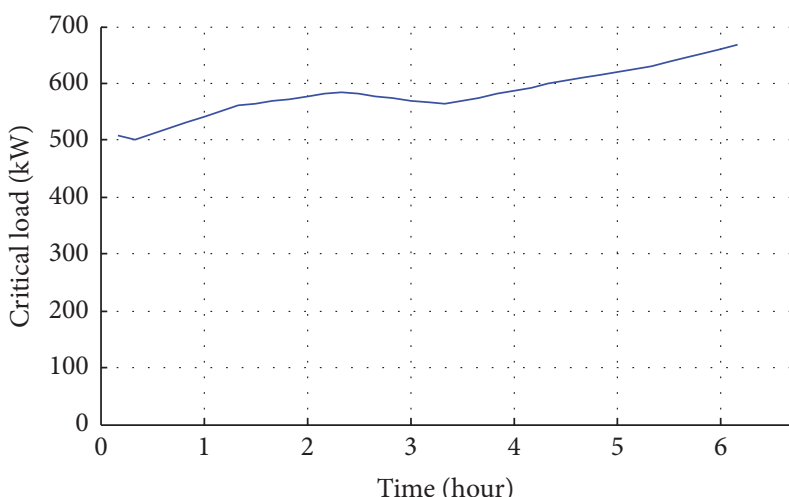

(a)

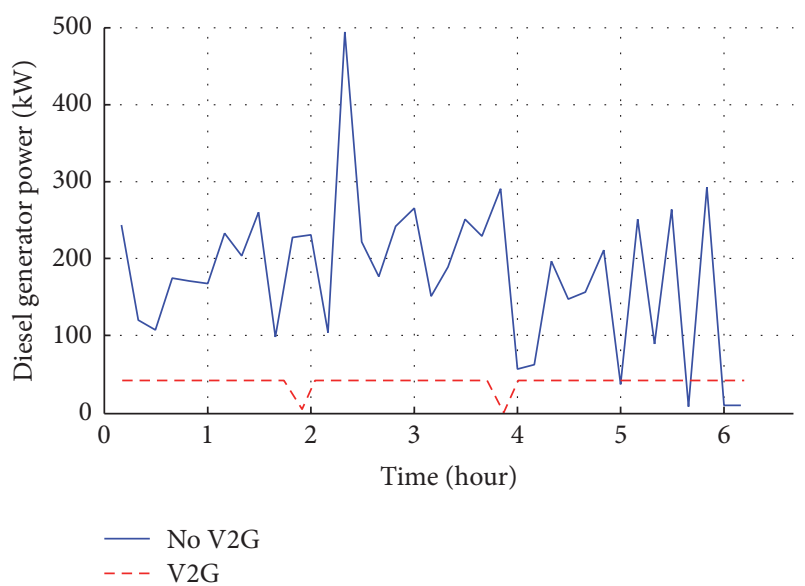

(c)

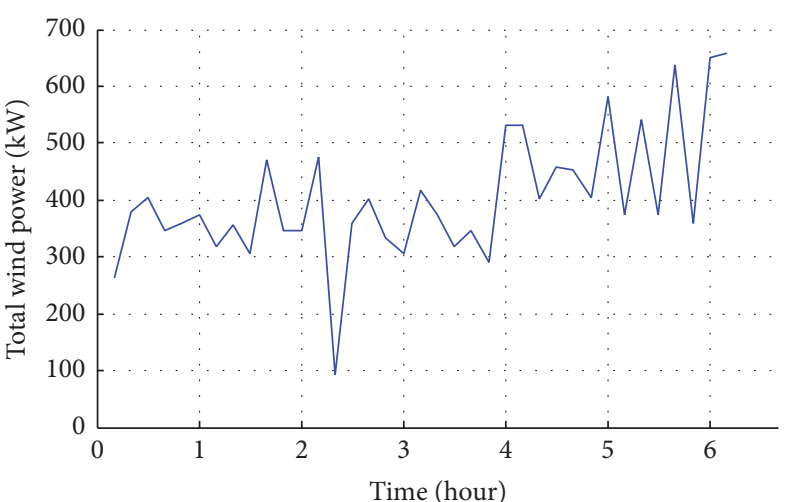

(b)

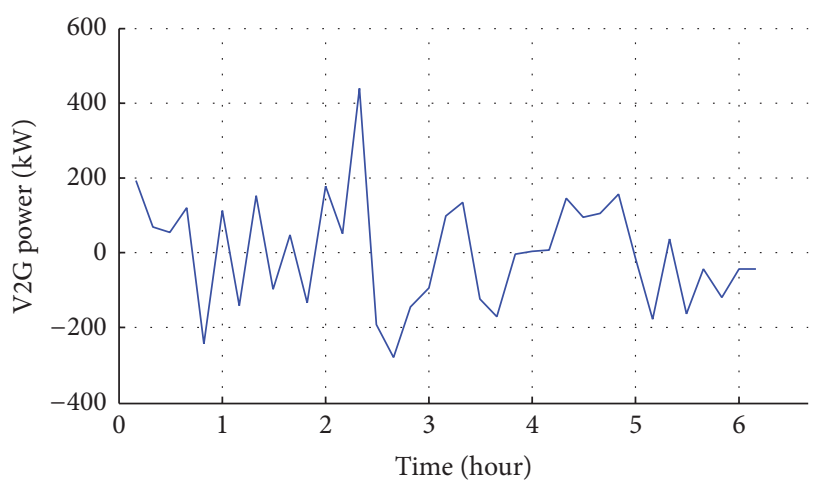

FIgURE 4: Simulation results for a windy isolation period.

the case where V2G is applied every day of the year. Prior to finding a model that considers the interests of all players of the game, policymakers cannot count on the success of vehicleto-grid idea in such a case.

\section{Appendix}

This appendix proves that the two-stage model proposed in this paper is equivalent to simultaneous maximization of Nash product with respect to both variables. The terms presented in (2) are expressed in other words in

$$
\max _{N, p} \operatorname{MGEP}(N, p) \times \operatorname{EVEP}(N, p),
$$

where $\operatorname{MGEP}(N, p)$ and $\operatorname{EVEP}(N, p)$ denote the excess payoffs of the microgrid operator and electric vehicles union, respectively, and can be written as follows:

$$
\begin{aligned}
\operatorname{MGEP}(N, p) & =\mathrm{MGC}_{\text {base }}-\mathrm{MGC}_{\mathrm{V} 2 \mathrm{G}}-N \times p, \\
\operatorname{EVEP}(N, p) & =N \times \mathrm{CVC}-N \times \mathrm{EVC}+N \times p .
\end{aligned}
$$

To maximize the Nash product presented in (A.1), its partial derivatives with respect to both $N$ and $p$ must be zero simultaneously. So we have

$$
\begin{aligned}
& \frac{\partial(\operatorname{MgEP}(N, p) \times \operatorname{EVEP}(N, p))}{\partial p}=0, \\
& \frac{\partial(\operatorname{MGEP}(N, p) \times \operatorname{EVEP}(N, p))}{\partial N}=0 .
\end{aligned}
$$

From (A.3), we have

$$
\begin{aligned}
& -N \times \operatorname{MgeP}(N, p) \times+N \times \operatorname{EVEP}(N, p)=0 \Longrightarrow \\
& \operatorname{MgeP}(N, p)=\operatorname{EVeP}(N, p) .
\end{aligned}
$$

And from (A.4),

$$
\begin{aligned}
& \frac{\partial \operatorname{MGEP}(N, p)}{\partial N} \times \operatorname{EVEP}(N, p)+\frac{\partial \operatorname{EVEP}(N, p)}{\partial N} \\
& \times \operatorname{MGEP}(N, p)=0 \Longrightarrow \\
& \left(-\frac{\partial \operatorname{MGC}_{\mathrm{V} 2 \mathrm{G}}(N)}{\partial N}-p\right) \times \operatorname{EVEP}(N, p) \\
& +(\mathrm{CVC}-\mathrm{EVC}+p) \times \operatorname{MGEP}(N, p)=0 .
\end{aligned}
$$




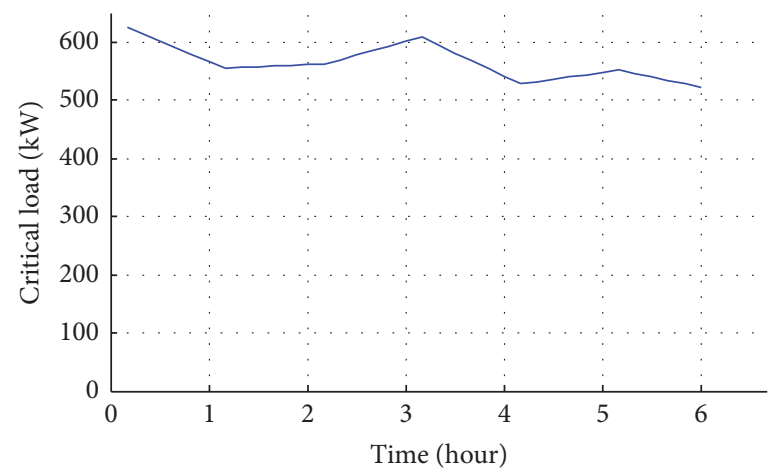

(a)

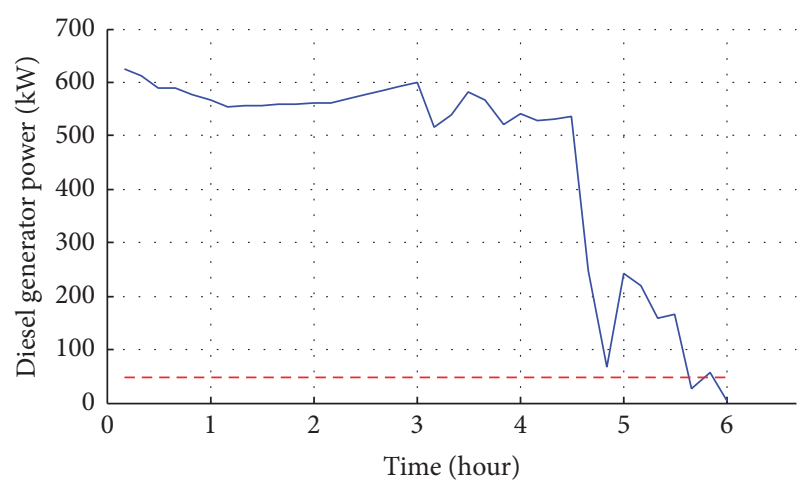

- No V2G

$---\mathrm{V} 2 \mathrm{G}$

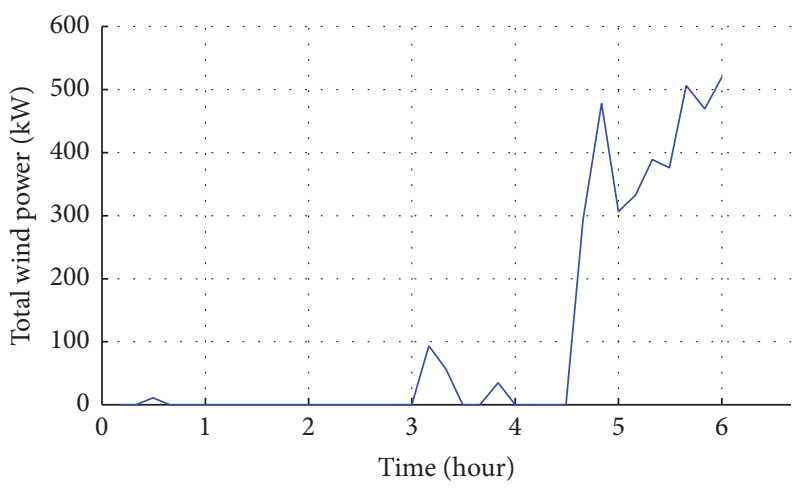

(b)

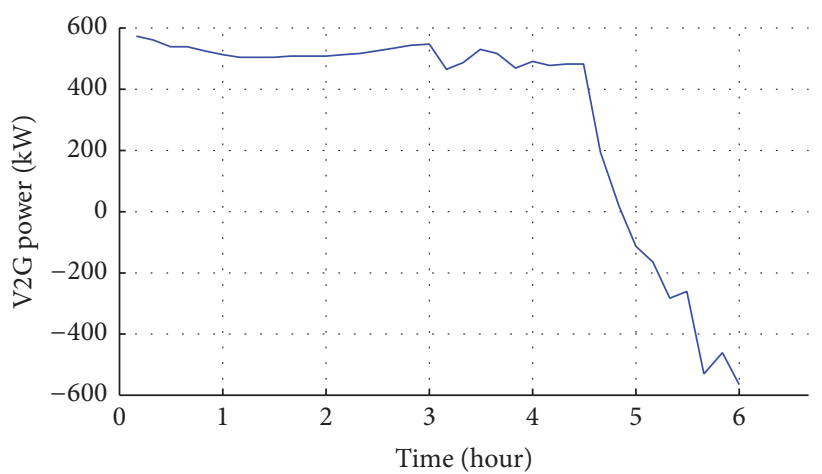

(d)

FIGURE 5: Simulation results for a low wind isolation period.

According to (A.5), in optimum of the Nash product function, the product terms are equal. Hence, we conclude

$$
\begin{gathered}
-\frac{\partial \mathrm{MGC}_{\mathrm{V} 2 \mathrm{G}}(N)}{\partial N}-p+\mathrm{CVC}-\mathrm{EVC}+p=0 \Longrightarrow \\
\frac{\partial \mathrm{MGC}_{\mathrm{V} 2 \mathrm{G}}(N)}{\partial N}-\mathrm{CVC}+\mathrm{EVC}=0 .
\end{gathered}
$$

The above equation is equivalent to (3) that had been proposed as the two-stage model. Furthermore, by substituting (A.2) into (A.5), the payment to the vehicles for V2G service-when the number of vehicles is optimal-will be the same as (4).

\section{Competing Interests}

The authors declare that they have no competing interests.

\section{References}

[1] S. Khan and A. Kushler, "Plug-in electric vehicles: challenges and opportunities. American council for an energy-efficient economy," 2013, http://www.aceee.org/research-report/t133.
[2] M. Duvall and E. Knipping, Environmental Assessment of PlugIn Hybrid Electric, Electric Power Research Institute (EPRI), 2007.

[3] A. Bandyopadhyay, L. Wang, V. K. Devabhaktuni, and R. C. Green, "Aggregator analysis for efficient day-time charging of Plug-in Hybrid Electric Vehicles," in Proceedings of the IEEE Power and Energy Society General Meeting, pp. 1-8, IEEE, Detroit, Mich, USA, July 2011.

[4] K. Clement, E. Haesen, and J. Driesen, "Coordinated charging of multiple plug-in hybrid electric vehicles in residential distribution grids," in Proceedings of the IEEE/PES Power Systems Conference and Exposition (PSCE '09), pp. 1-7, IEEE, Seattle, Wash, USA, March 2009.

[5] International Energy Agency, World Energy Outlook, 2011, http://www.iea.org/publications/freepublications/publication/ WEO2011_WEB.pdf.

[6] International Energy Agency, Global EV Outlook: Understanding the Electric Vehicle Landscape to 2020, 2013, http://www .iea.org/publications/freepublications/publication/GlobalEVOutlook_2013.pdf.

[7] H. Lee and G. Lovellette, "Will electric cars transform the U.S. vehicle market? An analysis of the key determinants," Discussion Paper 2011-08, Belfer Center for Science and International Affairs, Cambridge, Mass, USA, 2011.

[8] C. Hay, M. Togeby, N. C. Bang, C. Sondergren, and L. H. Hansen, Introducing Electric Vehicles into the Current Electricity Markets, EDISON Consortium, 2010. 
[9] C. Quinn, D. Zimmerle, and T. H. Bradley, "The effect of communication architecture on the availability, reliability, and economics of plug-in hybrid electric vehicle-to-grid ancillary services," Journal of Power Sources, vol. 195, no. 5, pp. 1500-1509, 2010.

[10] C. Guille and G. Gross, "A conceptual framework for the vehicle-to-grid (V2G) implementation," Energy Policy, vol. 37, no. 11, pp. 4379-4390, 2009.

[11] C. Guille and G. Gross, "Design of a conceptual framework for the V2G implementation," in Proceedings of the IEEE Energy 2030 Conference (ENERGY '08), pp. 1-3, November 2008.

[12] S. Han, S. Jang, K. Sezaki, and S. Han, "Quantitative modeling of an energy constraint regarding V2G aggregator for frequency regulation," in Proceedings of the 9th International Conference on Environment and Electrical Engineering (EEEIC '10), pp. 114-116, IEEE, Prague, Czech Republic, May 2010.

[13] N. Matta, R. Rahim-Amoud, L. Merghem-Boulahia, and A. Jrad, "A cooperative aggregation-based architecture for vehicleto-grid communications," in Proceedings of the Global Information Infrastructure Symposium (GIIS '11), pp. 1-6, Da Nang, Vietnam, August 2011.

[14] D. Wu, C. Liu, and S. Gao, "Coordinated control on a vehicleto-grid system," in Proceedings of the International Conference on Electrical Machines and Systems (ICEMS '11), pp. 1-6, Beijing, China, August 2011.

[15] J. Xu and V. W. S. Wong, "An approximate dynamic programming approach for coordinated charging control at vehicle-togrid aggregator," in Proceedings of the IEEE 2nd International Conference on Smart Grid Communications (SmartGridComm '11), pp. 279-284, IEEE, Gaithersburg, Md, USA, October 2011.

[16] M. El Chehaly, O. Saadeh, C. Martinez, and G. Joos, "Advantages and applications of vehicle to grid mode of operation in plugin hybrid electric vehicles," in Proceedings of the IEEE Electrical Power and Energy Conference (EPEC '09), pp. 1-6, Montreal, Canada, October 2009.

[17] H. Lund and W. Kempton, "Integration of renewable energy into the transport and electricity sectors through V2G," Energy Policy, vol. 36, no. 9, pp. 3578-3587, 2008.

[18] Y. Ota, H. Taniguchi, T. Nakajima, and K. M. Liyanage, "Autonomous distributed V2G (vehicle-to-grid) considering charging request and battery condition," in Proceedings of the IEEE PES Innovative Smart Grid Technologies Conference Europe (ISGT Europe), pp. 1-6, Gothenberg, Sweden, October 2010.

[19] R. Walawalkar, J. Apt, and R. Mancini, "Economics of electric energy storage for energy arbitrage and regulation in New York," Energy Policy, vol. 35, no. 4, pp. 2558-2568, 2007.

[20] W. Kempton, J. Tomic, S. Letendre, A. Brooks, and T. Lipman, Vehicle-to-Grid Power: Battery, Hybrid, and Fuel Cell Vehicles as Resources for Distributed, Institute of Transportation Studies (UCD), 2001.

[21] W. Kempton and J. Tomić, "Vehicle-to-grid power implementation: from stabilizing the grid to supporting large-scale renewable energy," Journal of Power Sources, vol. 144, no. 1, pp. 280-294, 2005.

[22] Y. Wang, B. Wang, C.-C. Chu, H. Pota, and R. Gadh, "Energy management for a commercial building microgrid with stationary and mobile battery storage," Energy and Buildings, vol. 116, pp. 141-150, 2016.

[23] W. Shi and V. W. S. Wong, "Real-time vehicle-to-grid control algorithm under price uncertainty," in Proceedings of the IEEE 2nd International Conference on Smart Grid Communications (SmartGridComm '11), pp. 261-266, IEEE, Brussels, Belgium, October 2011.
[24] E. Sortomme and M. A. El-Sharkawi, "Optimal charging strategies for unidirectional vehicle-to-grid," IEEE Transactions on Smart Grid, vol. 2, no. 1, pp. 131-138, 2011.

[25] M. A. Ortega-Vazquez, "Optimal scheduling of electric vehicle charging and vehicle-to-grid services at household level including battery degradation and price uncertainty," IET Generation, Transmission \& Distribution, vol. 8, no. 6, pp. 1007-1016, 2014.

[26] W. Kempton and J. Tomić, "Vehicle-to-grid power fundamentals: calculating capacity and net revenue," Journal of Power Sources, vol. 144, no. 1, pp. 268-279, 2005.

[27] J. Donadee and M. Ilić, "Stochastic co-optimization of charging and frequency regulation by electric vehicles," in Proceedings of the North American Power Symposium (NAPS '12), pp. 1-6, Champaign, Ill, USA, September 2012.

[28] J. Lee and G.-L. Park, "A heuristic-based electricity trade coordination for microgrid-level V2G services," International Journal of Vehicle Design, vol. 69, no. 1-4, pp. 208-223, 2015.

[29] C. M. Colson, M. H. Nehrir, and C. Wang, "Ant colony optimization for microgrid multi-objective power management," in Proceedings of the IEEE/PES Power Systems Conference and Exposition (PSCE '09), pp. 1-7, Seattle, Wash, USA, March 2009.

[30] B. Kroposki, T. Basso, and R. DeBlasio, "Microgrid standards and technologies," in Proceedings of the IEEE Power and Energy Society General Meeting: Conversion and Delivery of Electrical Energy in the 21st Century (PES '08), pp. 1-4, IEEE, Pittsburgh, $\mathrm{Pa}$, USA, July 2008.

[31] A. D. Hawkes and M. A. Leach, "Modelling high level system design and unit commitment for a microgrid," Applied Energy, vol. 86, no. 7-8, pp. 1253-1265, 2009.

[32] C. A. Hernandez-Aramburo, T. C. Green, and N. Mugniot, "Fuel consumption minimization of a microgrid," IEEE Transactions on Industry Applications, vol. 41, no. 3, pp. 673-681, 2005.

[33] M. T. Lawder, V. Viswanathan, and V. R. Subramanian, "Balancing autonomy and utilization of solar power and battery storage for demand based microgrids," Journal of Power Sources, vol. 279, pp. 645-655, 2015.

[34] A. Mohd, E. Ortjohann, A. Schmelter, N. Hamsic, and D. Morton, "Challenges in integrating distributed energy storage systems into future smart grid," in Proceedings of the IEEE International Symposium on Industrial Electronics (ISIE '08), pp. 1627-1632, Cambridge, UK, June 2008.

[35] P. Han, J. Wang, Y. Han, and Y. Li, "Resident Plug-In Electric Vehicle charging modeling and scheduling mechanism in the smart grid," Mathematical Problems in Engineering, vol. 2014, Article ID 540624, 8 pages, 2014.

[36] P. Denholm and R. Sioshansi, "The value of plug-in hybrid electric vehicles as grid resources," in Proceedings of the 34th IAEE International Conference, Stockholm, Sweden, 2011.

[37] C. Quinn, D. Zimmerle, and T. H. Bradley, "An evaluation of state-of-charge limitations and actuation signal energy content on plug-in hybrid electric vehicle, vehicle-to-grid reliability, and economics," IEEE Transactions on Smart Grid, vol. 3, no. 1, pp. 483-491, 2012.

[38] P. Manzini, "Game theoretic models of wage bargaining," Journal of Economic Surveys, vol. 12, no. 1, pp. 1-41, 1998.

[39] A. Muthoo, Bargaining Theory with Applications, Cambridge University Press, Cambridge, UK, 1999.

[40] A. E. Roth, Game-Theoretic Models of Bargaining, Cambridge University Press, Cambridge, UK, 2005.

[41] M. H. Sarparandeh, M. Moeini-Aghtaie, P. Dehghanian, I. Harsini, and A. Haghani, "Feasibility study of operating an autonomous power system in presence of wind turbines, A 
practical experience in Manjil, Iran," in Proceedings of the 11th International Conference on Environment and Electrical Engineering (EEEIC '12), pp. 1011-1016, Venice, Italy, May 2012.

[42] K. Y. Lee and M. A. El-Sharkawi, Modern Heuristic Optimization Techniques: Theory and Applications to Power Systems, WileyIEEE Press, 2008.

[43] H. L. Willis and W. G. Scott, Distributed Power Generation Planning and Evaluation, Marcel Dekker, New York, NY, USA, 2000.

[44] K. Qian, C. Zhou, M. Allan, and Y. Yuan, "Modeling of load demand due to EV battery charging in distribution systems," IEEE Transactions on Power Systems, vol. 26, no. 2, pp. 802-810, 2011. 


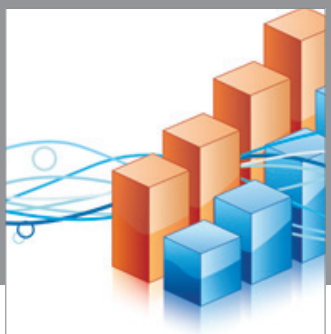

Advances in

Operations Research

vatem alat4

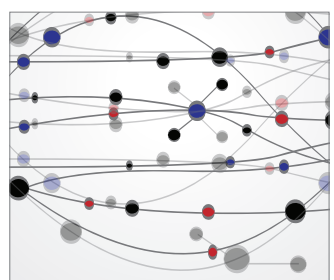

\section{The Scientific} World Journal
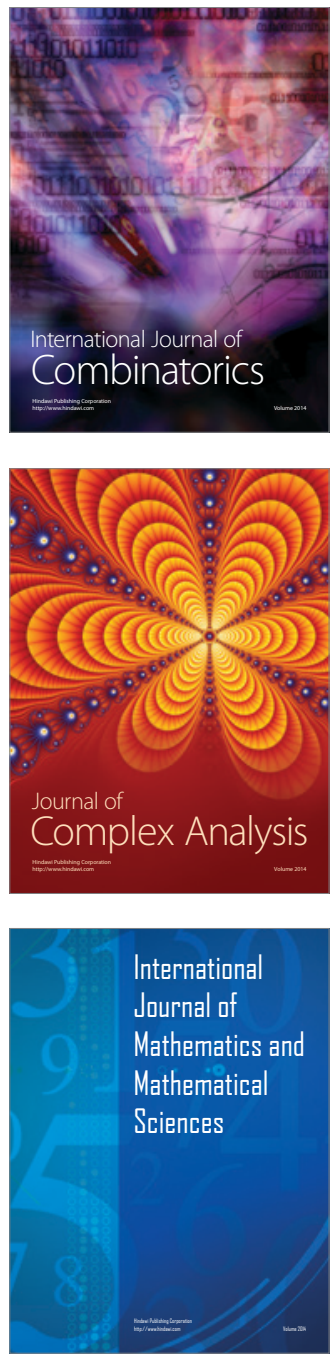
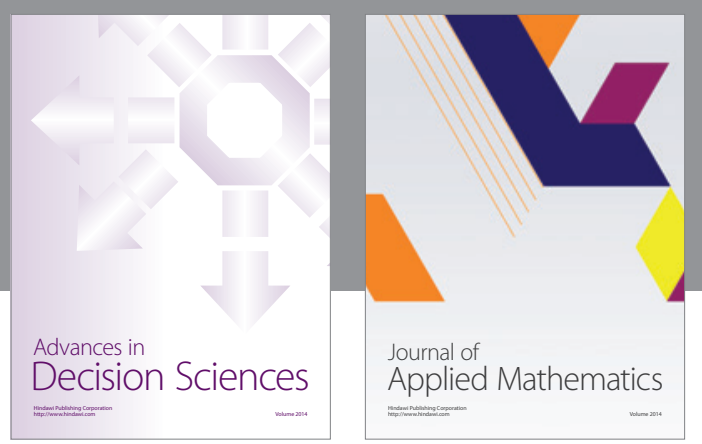

Algebra

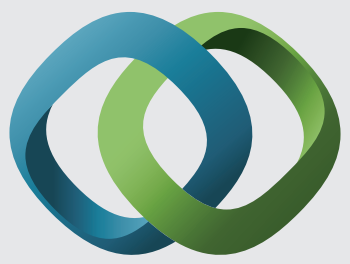

\section{Hindawi}

Submit your manuscripts at

https://www.hindawi.com
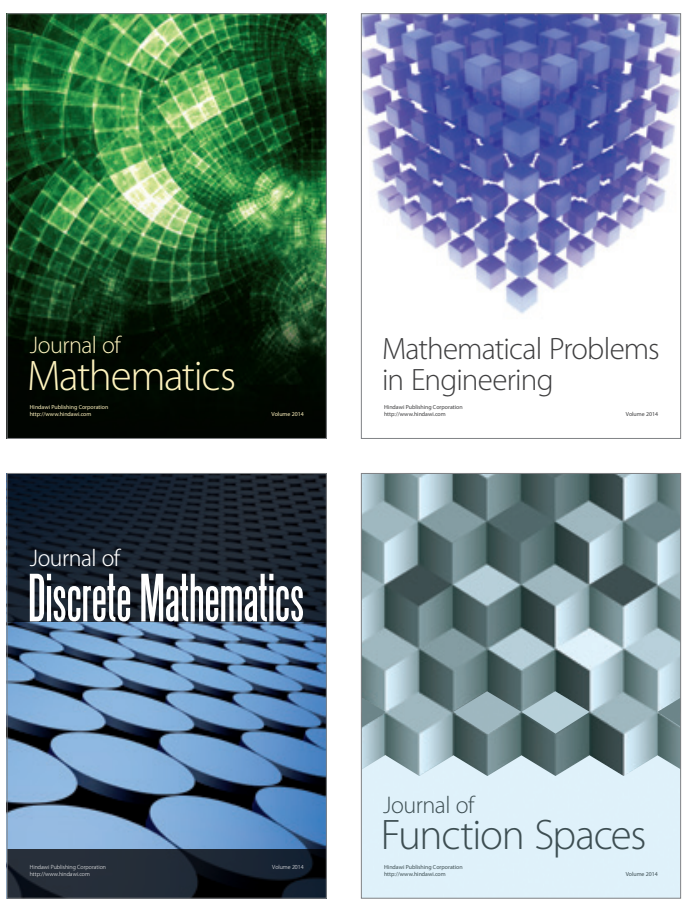

Mathematical Problems in Engineering
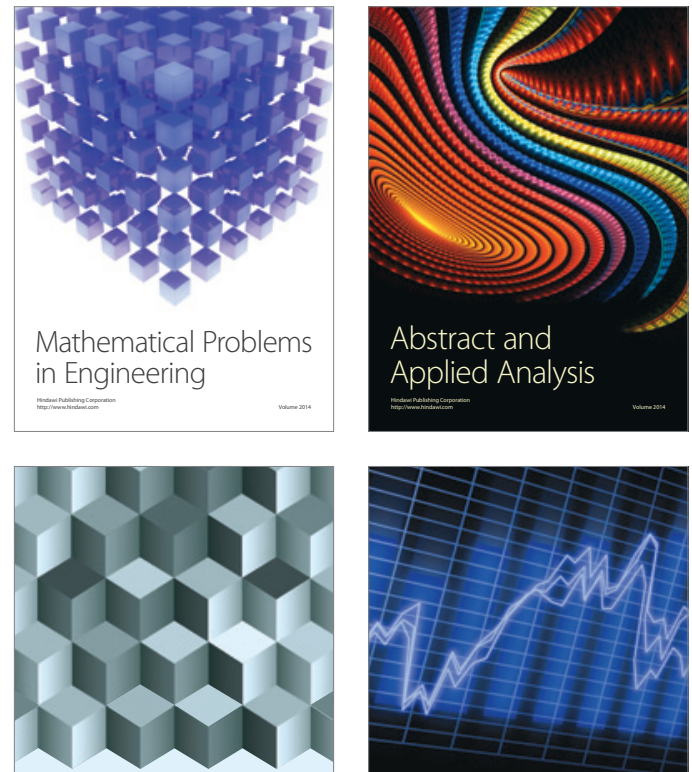

Journal of

Function Spaces

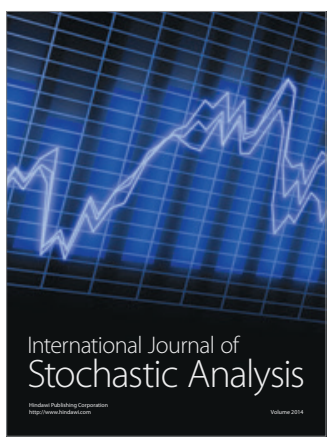

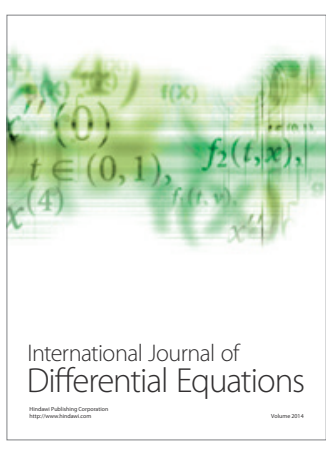
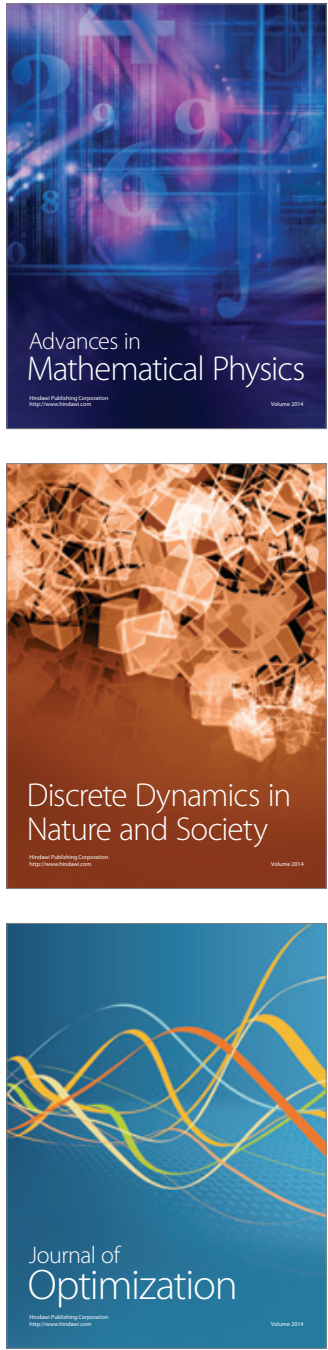